\title{
Effects of Hydroquinone on Cytoskeletal Organization and Intracellular Transport in Cultured Xenopus laevis Melanophores and Fibroblasts
}

\author{
Sara Aspengren, ${ }^{1}$ Elisabeth Norström, ${ }^{2}$ and Margareta Wallin ${ }^{2}$ \\ ${ }^{1}$ Cellectricon AB, Flöjelbergsgatan 8C, 43137 Mölndal, Sweden \\ ${ }^{2}$ Department of Zoology/Zoophysiology, Göteborg University, P.O. Box 463, 40530 Göteborg, Sweden
}

Correspondence should be addressed to Sara Aspengren, sara.aspengren@cellectricon.com

Received 10 October 2011; Accepted 13 November 2011

Academic Editors: Y. Gachet, C. C. Uphoff, and Y. Zhang

Copyright ( 2012 Sara Aspengren et al. This is an open access article distributed under the Creative Commons Attribution License, which permits unrestricted use, distribution, and reproduction in any medium, provided the original work is properly cited.

\begin{abstract}
Hydroquinone is used as a skin-lightening agent, it is also present in different chemical products and cigarette smoke. It is believed to inhibit melanin production in melanocytes by inhibiting the key enzyme tyrosinase. In the present study, we show that hydroquinone had severe effects on microtubules and actin filaments in cultured Xenopus laevis melanophores as studied by immunohistochemistry. It affected the intracellular transport of melanosomes, induced bundling of microtubules and disassembly of actin filaments at 10 and $50 \mu \mathrm{M}$, and at $100 \mu \mathrm{M}$ proper adhesion to the substrate was lost. Effects occurred at lower concentrations than what previously has been stated to be cytotoxic, and the results show that tyrosinase is not the only cellular target. The cytoskeleton is of utmost importance for the function of all cells and across species. Our data has therefore to be considered in the discussions about the use of hydroquinone for bleaching of skin.
\end{abstract}

\section{Introduction}

Hydroquinone (HQ) is a synthetically produced and naturally occurring chemical that is used for example in cosmetics as a skin-lightening agent, as a reagent in photographic developers, and in rubber manufacture [1]. It is also present in significant levels in cigarette smoke [2]. Genomic and proteomic analyses have shown that HQ treatment induces changes in proteins that are involved in for instance oxidative stress, focal adhesion, cellular signalling, and cytoskeleton reconstruction [1-3].

As a skin-lightening agent, HQ is believed to act by inhibition of the enzyme tyrosinase, thereby reducing the conversion of dihydroxybenzoic acid (DOPA) to melanin $[4,5]$. Administration of HQ induces reduced pigmentation in mammals [6] and has been suggested to have a selective melanotoxic action. Using melanocytes and nonmelanotic cells, it has been demonstrated that sensitivity to the cytotoxic effects of HQ is associated with the presence of tyrosinase activity [7], and cytotoxicity is increased when cells are exposed to UVA radiation [8]. Uncontrolled use of HQcontaining bleaching products has resulted in an epidemic of postinflammatory hyperpigmentation (exogenous ochronosis) in South Africa $[9,10]$. Due to the toxicological side effects the use of HQ in cosmetics has been banned in the European Union [11], but it is still allowed in many countries.

In order to gain further insight in potential mechanism(s) of action and cellular effects of HQ, we have used immortalized melanophores from the African clawed frog, Xenopus laevis. Melanophores derive from the neural crest and are cells specialized for rapid and synchronous intracellular transport of pigmented organelles, melanosomes [12]. Melanophores from lower vertebrates provide an excellent model not only to study pigmentation per se, but also more generally for studies of organelle transport. Movements of the black melanosomes can be easily visualized with light microscopy and the direction of transport can be regulated. We have recently established that these cells can be valuable for toxicological studies $[13,14]$. 
The cellular organizations of actin filaments and microtubules are severely affected even at concentrations lower than what has previously been stated to be cytotoxic. Our results therefore show that tyrosinase is not the only cellular target for HQ even if pigmented cells were more sensitive to HQ than nonpigmented cells. Due to the cellular importance of the cytoskeleton, for example, in cell division, intracellular transport, movement of sperms, and skeletal function, the use of HQ especially as a depigmentating compound should be carefully reviewed.

\section{Experimental Procedures}

2.1. Materials. Melatonin, $\alpha-\mathrm{MSH}$, and phenylthiocarbamide were from Sigma (St. Louis, MO, USA). HQ was from Fluka (Buchs, Switzerland). Stock solutions of melatonin and $\alpha$-MSH were stored at $-20^{\circ} \mathrm{C}$ and diluted to the experimental concentrations in fresh medium just before use. Fresh stock solution of HQ was made just before each experiment. The $\alpha$-tubulin antibody was from Sigma, the rhodamin marked phalloidin and the Alexa Fluor 594-conjugated secondary antibodies were from Molecular Probes (Eugene, OR, USA).

2.2. Cell Culture. Xenopus laevis fibroblasts and melanophores were generously provided by Michael Lerner, Arena Pharmaceuticals. The fibroblasts were cultured in 0.7-x Leibovitz L-15 medium at $27^{\circ} \mathrm{C}$. The medium was diluted with sterile water and supplemented with $20 \%$ fetal bovine serum, $2 \mathrm{mM}$ L-glutamine, $100 \mathrm{IU} / \mathrm{ml}$ penicillin, and $100 \mu \mathrm{g} / \mathrm{ml}$ streptomycin. Medium that had been conditioned by fibroblasts for 3 to 4 days was then used in the melanophore culture. For depigmentation, melanophores were cultured in phenylthiocarbamide diluted in conditioned medium $(900 \mu \mathrm{M})$ for at least six weeks. Cell culture reagents were obtained from Life Technologies (Renfrewshire, Scotland) and cell culture plastics were from Sarstedt (Nümbrecht, Germany).

2.3. Light Microscopy. Pigment cells were sparsely seeded in 6-well culture plates and were allowed to rest for 3 days. Half of the cells were equilibrated with light and serum-free medium for $2 \mathrm{~h}$ before observation and photography. After incubation with HQ for $24 \mathrm{~h}$, the cells were photographed again. Thereafter the cells were incubated with melatonin in order to induce melanosome aggregation and after $90 \mathrm{~min}$ they were photographed once more. The remaining cells were induced to aggregate with melatonin and serum-free medium in the dark for $2 \mathrm{~h}$ before observation and photography using a Nikon light microscope. After incubation with HQ together with melatonin for $24 \mathrm{~h}$, the cells were photographed for a second time. Thereafter, the cells were incubated with $\alpha$-MSH in order to induce melanosome dispersion, and after 90 min they were photographed again.

2.4. Immunocytochemistry. Cells were seeded on coverslips and cultured for 2 days. In order to fully induce aggregation, pigmented melanophores were exposed to melatonin $(10 \mathrm{nM})$ in serum-free medium and dark for 2 hours. Cells were then incubated with HQ at three different concentrations $(10 \mu \mathrm{M}, 50 \mu \mathrm{M}$, and $100 \mu \mathrm{M})$ for $24 \mathrm{~h}$. Control cells were incubated with serum free medium.

For immunostaining of microtubules, melanophores were fixed in $-20^{\circ} \mathrm{C}$ methanol for $6 \mathrm{~min}$ and then washed three times with PBS before incubation with the $\alpha$-tubulin primary antibody for $50 \mathrm{~min}$ at room temperature. The cells were washed three times with PBS and incubated in darkness with the secondary antibody for $40 \mathrm{~min}$. Thereafter, the cells were washed with PBS again and briefly rinsed in water before they were allowed to dry in air. Controls were performed in the absence of primary antibodies.

For immunostaining of actin filaments, the cells were rinsed in PBS, fixed in 3.7\% formaldehyde solution for 10 minutes, washed twice with PBS, and incubated in $0.1 \%$ TRITON X-100 for $5 \mathrm{~min}$. The cells were incubated with $1 \%$ BSA for $20 \mathrm{~min}$ to avoid unspecific staining. The cells were then stained with rhodamin phalloidin for $20 \mathrm{~min}$, washed in PBS, and allowed to dry in air.

All coverslips were mounted in DABCO mixed with glycerol and examined in a Nikon fluorescence microscope.

\section{Results}

3.1. HQ Inhibits the Dispersed State and Induces Aggregation of Melanosomes. The effect of HQ on cytoskeleton-dependent transport of melanosomes was first studied on cells that had been dispersed by equilibration in serum-free medium and light(Figure $1(\mathrm{a}))$. After $24 \mathrm{~h}$ of incubation, control cells and cells treated with the lowest dose $(10 \mu \mathrm{M})$ of HQ were still dispersed (Figure 1(b)). Melanophores incubated with the higher doses $(50 \mu \mathrm{M}$ and $100 \mu \mathrm{M})$ of HQ changed morphology dramatically and became smaller and more dendritic. The melanosomes were assembled either in the cell centre or in the slender dendrites. In addition, in cultures treated with $100 \mu \mathrm{M} \mathrm{HQ}$, cell adhesion was affected and substantial amounts of cells were detached during the $24 \mathrm{~h}$ incubation.

Addition of melatonin to dispersed control cells induced aggregation. Most cells aggregated the melanosomes to a central pigment mass, but in some cells the melanosomes aggregated towards a central part of the cell leaving an inner melanosome-free spot (Figure 1(c)). Aggregation was also induced by melatonin in cells treated with $10 \mu \mathrm{M} \mathrm{HQ}$, but the amount of cells with a melanosome-free central part seemed to increase. In cells treated with the higher doses of HQ, melatonin did not induce any further aggregation.

3.2. HQ Inhibits Dispersion of Melanosomes. Next, cells were incubated with melatonin in serum-free medium for $2 \mathrm{~h}$ in order to induce aggregation (Figure 2(a)). HQ was added and cells were further incubated for $24 \mathrm{~h}$. Control cells and cells treated with 10 or $50 \mu \mathrm{M}$ HQ were still aggregated, but in plates incubated with $100 \mu \mathrm{M} \mathrm{HQ}$, the central pigment mass was loosened and cells were frequently detaching from the plastic (Figure 2(b)). Large amounts of extracellular melanosomes were observed in the culture medium (not shown). After incubation with $\alpha$-MSH, control cells and 

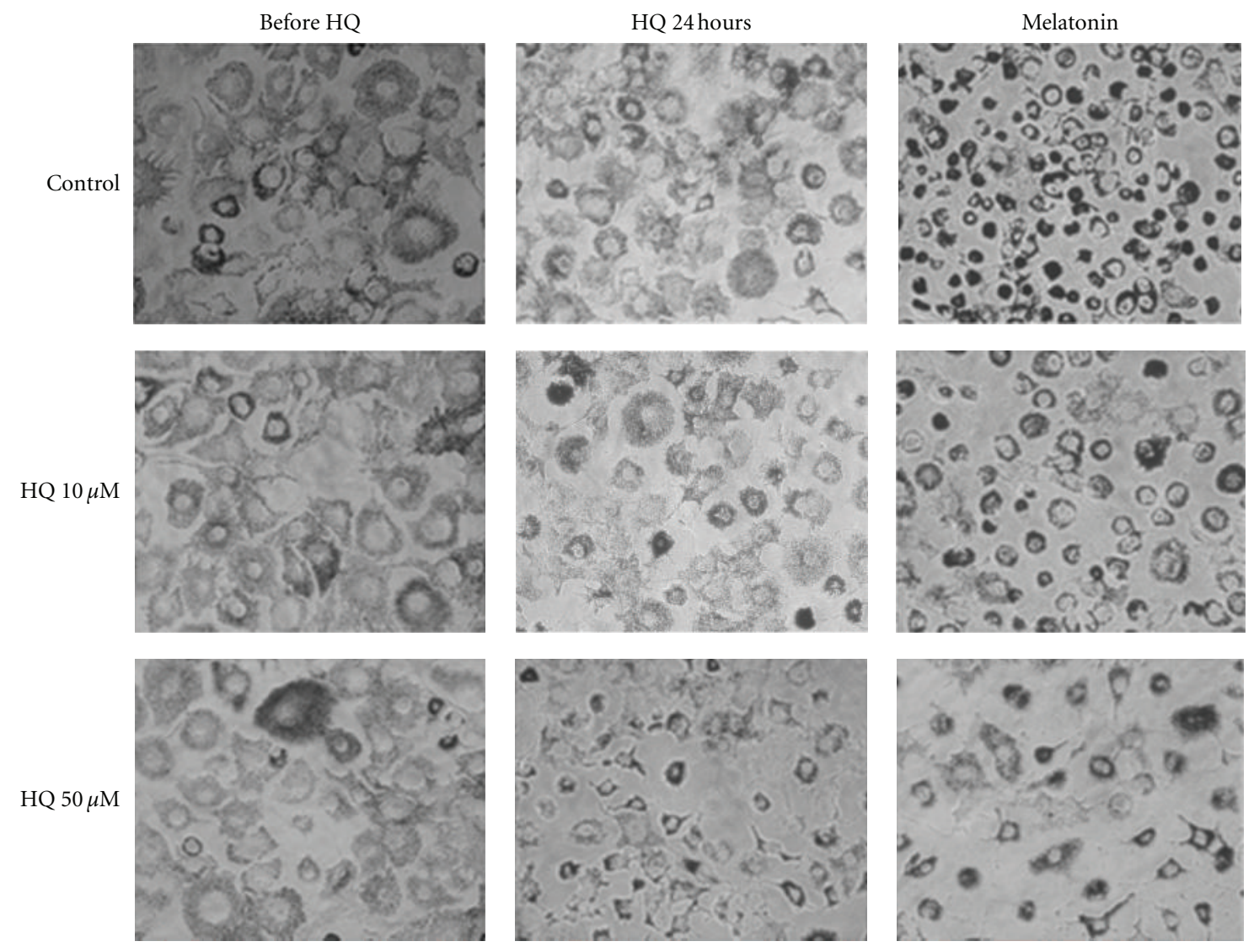

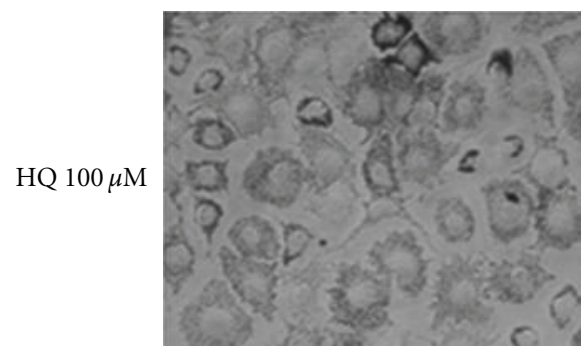

(a)

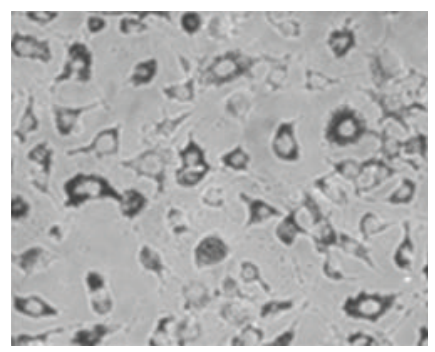

(b)

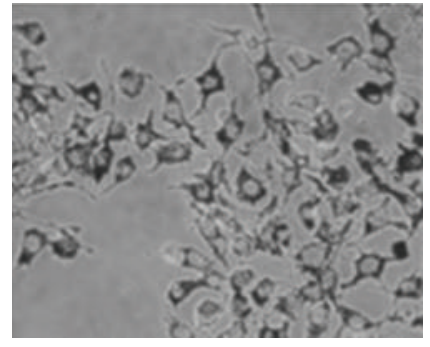

(c)

FIGURE 1: Micrographs showing melanosome distributions before and after treatment with HQ. (a) Cells have been equilibrated in light for $2 \mathrm{~h}$ to stimulate dispersion. (b) shows cells that have been incubated with HQ for $24 \mathrm{~h}$. Control cells were incubated in serum-free medium. In (c), all cells have been incubated with melatonin for $90 \mathrm{~min}$ to induce aggregation.

cells treated with $10 \mu \mathrm{M}$ HQ had dispersed melanosomes (Figure 2(c)). In cells treated with $50 \mu \mathrm{M}$ HQ dispersion was somewhat inhibited, and the pigment was not distributed all the way out in the dendritic arms. At $100 \mu \mathrm{M} H Q$, dispersion was almost completely inhibited. Melanosomes were mainly clumped together in the cell center, and aggregates could also be found in the dendritic arms.

3.3. HQ Affects Cytoskeletal Morphology. The light microscopy results indicate that HQ has an impact on the melanophore cytoskeleton, and we used antibodies directed against tubulin and rhodamin-labelled phalloidin to study the effects of HQ on melanophore microtubules and actin filaments. It has been previously implied that sensitivity to the cytotoxic effects of HQ is associated with the presence of tyrosinase activity [7], and in order to investigate whether pigment-containing cells are more sensitive we also imaged the cytoskeleton in fibroblasts and depigmented melanophores. Depigmented melanophores have no active pigment production, and fibroblasts lack the ability to produce melanin. The black melanosomes quench some fluorescence, and therefore the pigmented melanophores were preaggregated with melatonin before incubation with drugs and immunostaining. Due to their reduced adhesion to the substrate, effects on the cytoskeleton could not be studied in cells treated with $100 \mu \mathrm{M}$ HQ. They detached from the cover slips during the staining procedure. 

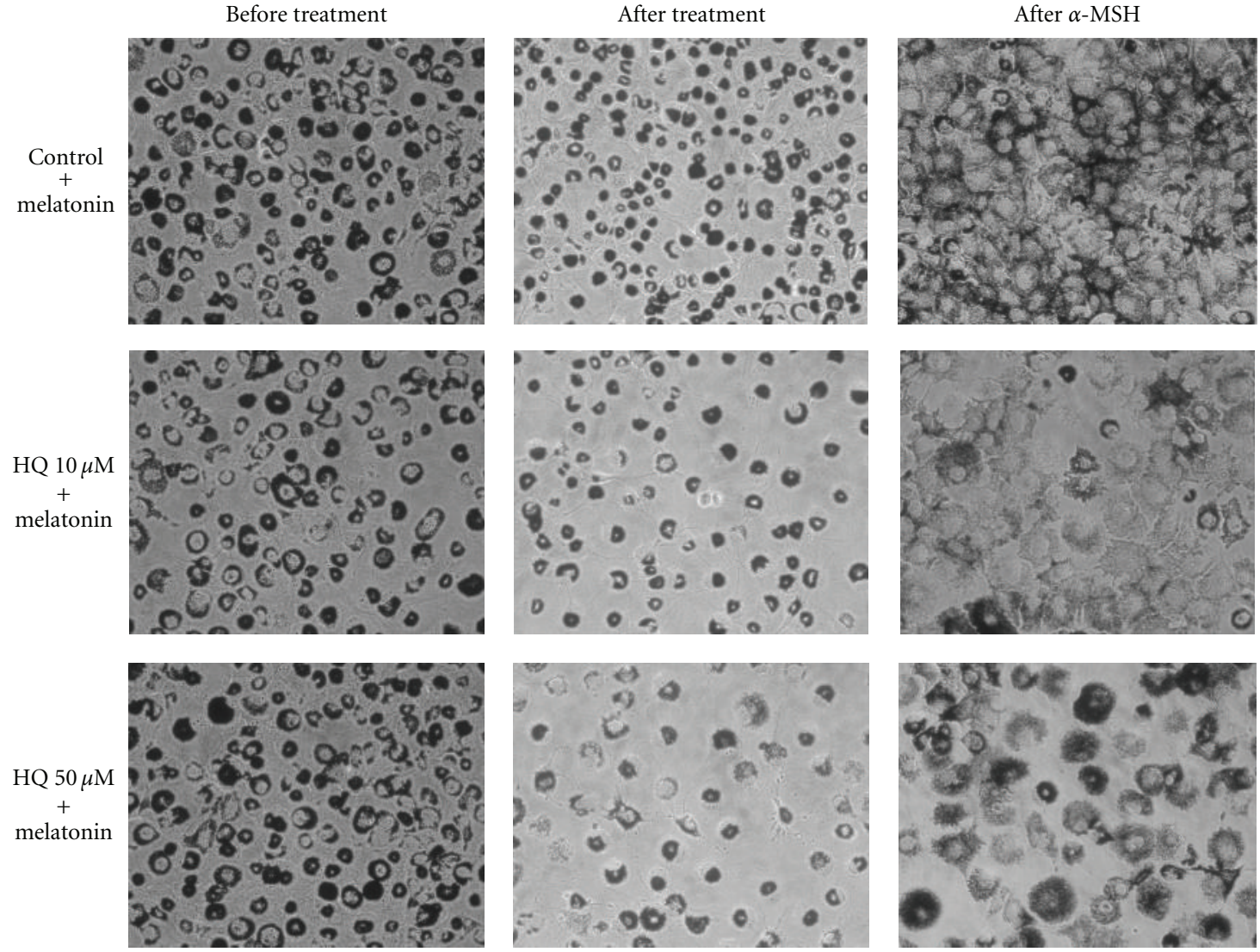

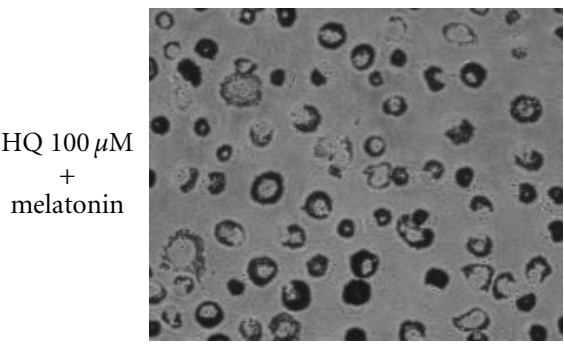

(a)

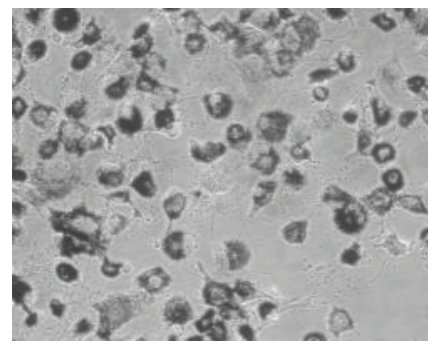

(b)

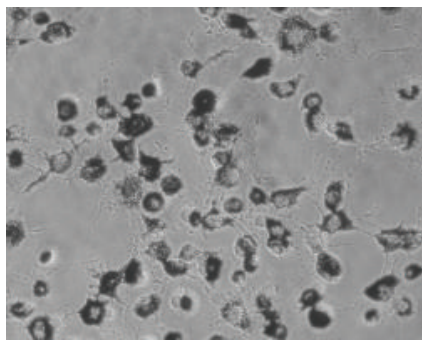

(c)

FIGURE 2: Micrographs showing melanosome distributions before and after treatment with HQ. In (a) cells have been preaggregated with melatonin in darkness for $2 \mathrm{~h}$. (b) shows cells that have been incubated with HQ together with melatonin for $24 \mathrm{~h}$. Control cells were incubated in serum-free medium with melatonin. In (c), all cells have been incubated with $\alpha$-MSH for 90 min to induce dispersion.

In untreated melanophores, pigmented as well as depigmented microtubules radiate from the cell centre to the periphery in a complicated network (Figures $3(\mathrm{a})$ and $3(\mathrm{~d})$ ). After incubation with $10 \mu \mathrm{M} \mathrm{HQ}$, the microtubules were mostly unaffected, but in some cells microtubules were bundled in the central parts of the cell but remained individual in the periphery (Figures 3(b) and 3(e)). The cellular organization of microtubules was severely affected in pigmented melanophores treated with $50 \mu \mathrm{M} \mathrm{HQ}$ (Figure 3(c)). The microtubules appeared to be bundled and were thicker than in control cells. The microtubules in depigmented melanophores were much less affected and no bundles were observed (Figure 3(f)). Microtubules in fibroblasts also radiate from the cell centre to the periphery, and HQ did not affect the $\alpha$-tubulin distribution in any of the concentrations tested (Figures 3(g)-3(i)).

The cellular organization of actin filaments is less structured then microtubules, but in melanophores a diffuse network and microspikes could be observed in untreated cells (Figures 4(a) and 4(d)). In cells treated with $10 \mu \mathrm{M} \mathrm{HQ}$, there was an increase in the amount of stress fibers spanning the cytoplasm (Figures 4(b) and 4(e)). The actin network was completely disrupted in pigmented melanophores treated with $50 \mu \mathrm{M}$ HQ (Figure 4(c)), but in depigmented cells stress fibers were intact (Figure 4(f)). Again, fibroblasts withstood the HQ treatment much better than pigmented melanophores, although there was an increase in stress fibers compared to control cells (Figures 4(g)-4(i)). 
Control

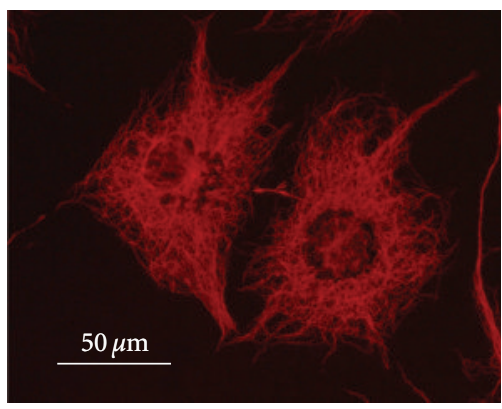

(a)

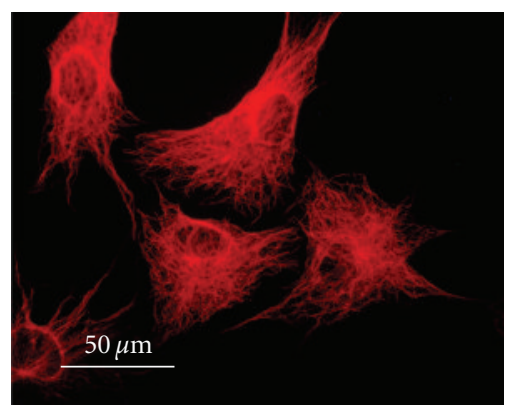

(d)

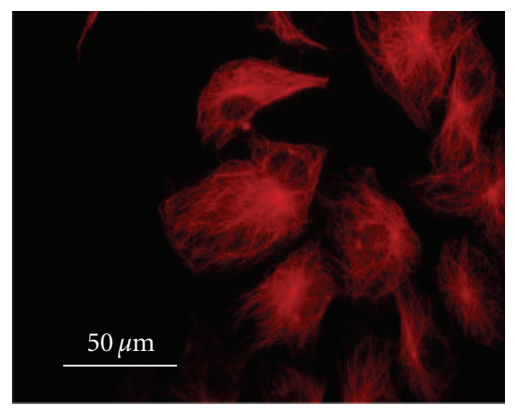

(g)
$10 \mu \mathrm{M} \mathrm{HQ}$

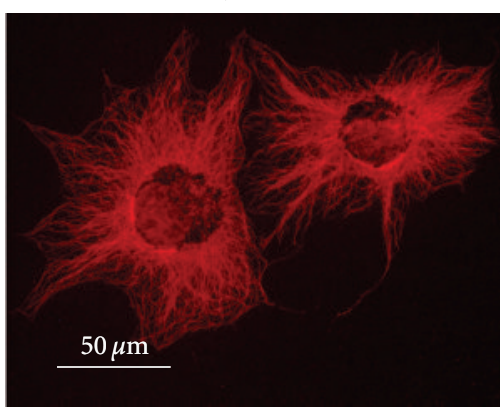

(b)

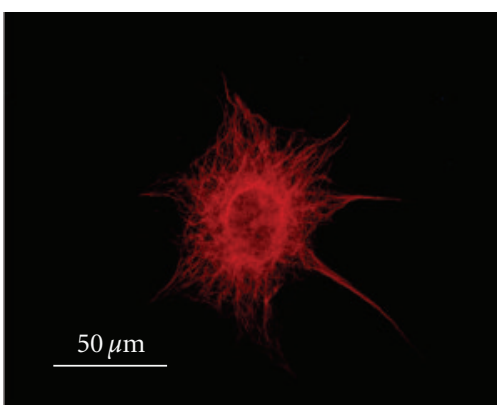

(e)

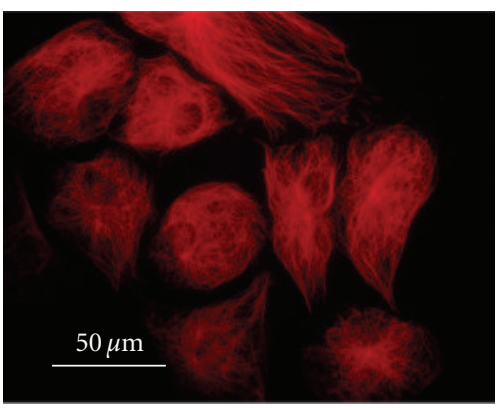

(h)

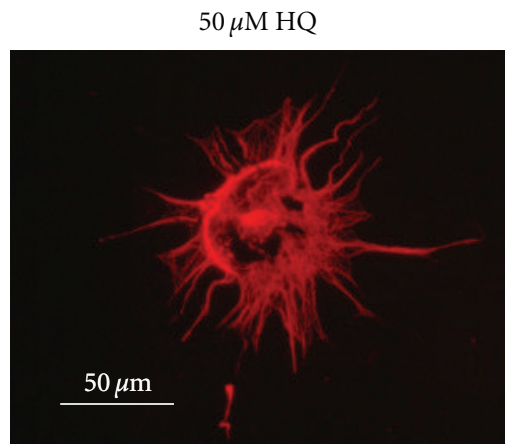

(c)

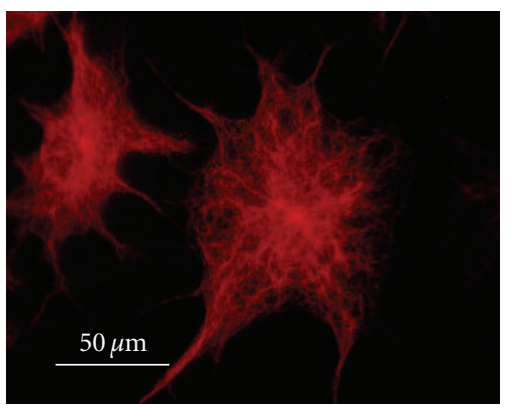

(f)

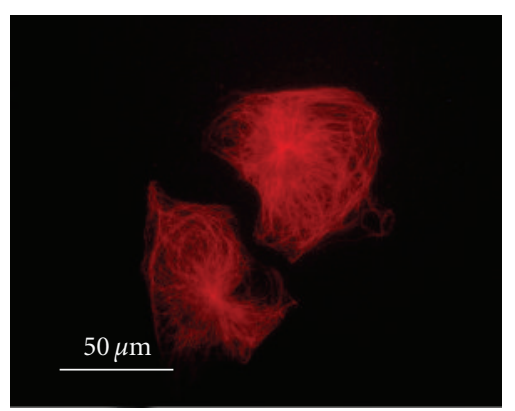

(i)

FIGURE 3: Distribution of microtubules in cultured melanophores and fibroblasts, revealed by immunoreactivity. Scale bar $=50 \mu \mathrm{m}$. $(\mathrm{a}-\mathrm{c})$ : pigmented melanophores with aggregated pigment. (d-f): depigmented melanophores. (g-i): fibroblasts.

\section{Discussion}

HQ was found to affect transport and intracellular localization of melanosomes in melanophores, functions that are highly dependent on the organization of microtubules and actin filaments. HQ induced reorganization of microtubules into thin bundles, while all actin filaments and stress fibres disassembled. We have previously found that the toxic substance acrylamide can induce microtubule bundles, and the same effect is seen when using the actin-depolymerizing drug latrunculin, showing interdependence between microtubules and actin filaments [13]. However, microtubule bundles induced by acrylamide and latrunculin were thicker than those seen after incubation with HQ.

The effects of HQ were concentration-dependent. At the lowest concentration, $10 \mu \mathrm{M} \mathrm{HQ}$, some microtubule-bundling was seen and compared to control cells more melanophores had a central melanosome-free spot after melatonininduced aggregation, indicating that the ability to change color is affected. At $50 \mu \mathrm{M}$ HQ dispersion could be induced by addition of $\alpha-\mathrm{MSH}$ in spite of the lack of actin filaments, showing that melanosomes can be transported along the reorganized microtubules. This effect differs from what is previously known from removal of actin-filaments by latrunculin, which induces aggregation of melanosomes in Xenopus [13, 15], and a marked bundling of microtubules [13]. No dispersion can be induced by $\alpha$-MSH in latrunculintreated cells, even if microtubules are present. These data underlines that the cellular organization of microtubules and actin filaments are highly dependent on each other, and our data suggests that the ability to transport melanosomes along microtubule bundles might depend on how microtubules are organized within the bundles. The mechanism for this is unclear, but one cannot exclude the possibility that steric hindrance of binding of the microtubule motor kinesin may be involved. The cytoskeleton in fibroblasts and depigmented melanophores was much less affected, indicating that the 
Control

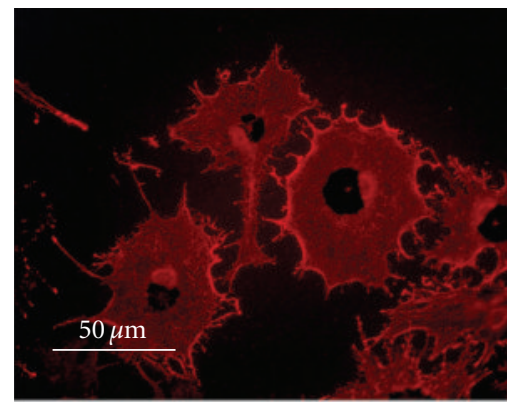

(a)

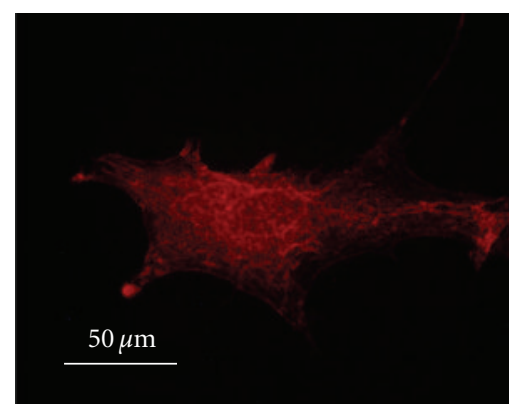

(d)

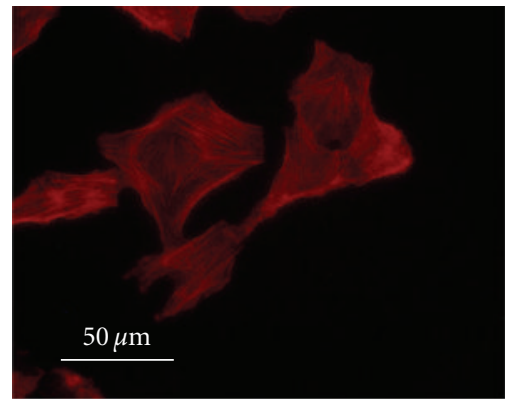

(g)
$10 \mu \mathrm{M}$ HQ

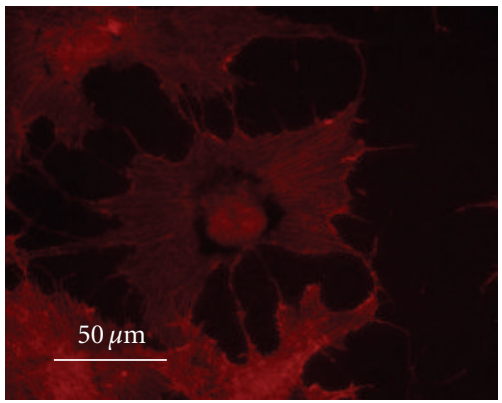

(b)

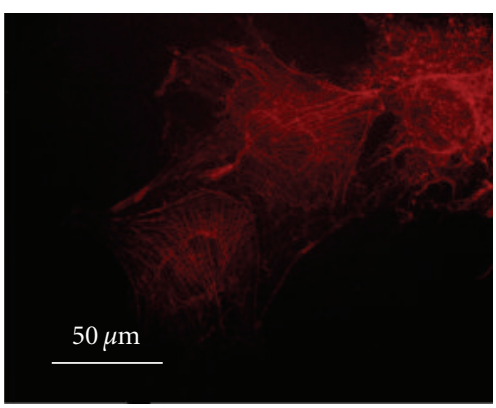

(e)

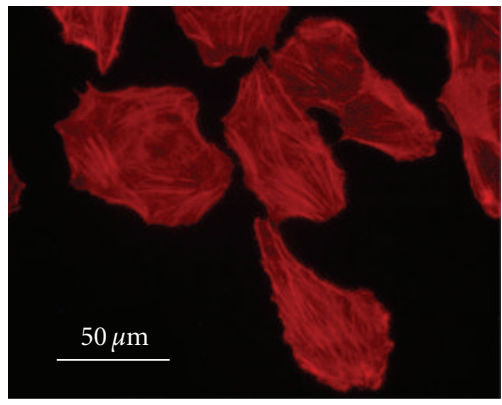

(h)
$50 \mu \mathrm{M}$ HQ

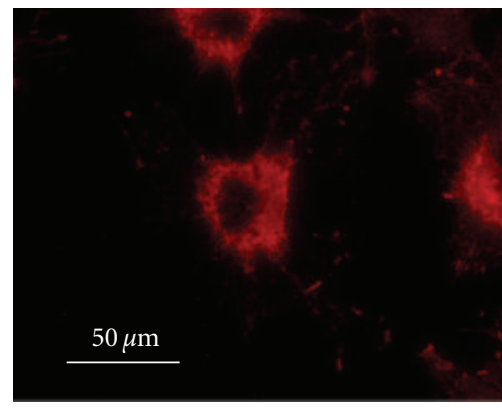

(c)

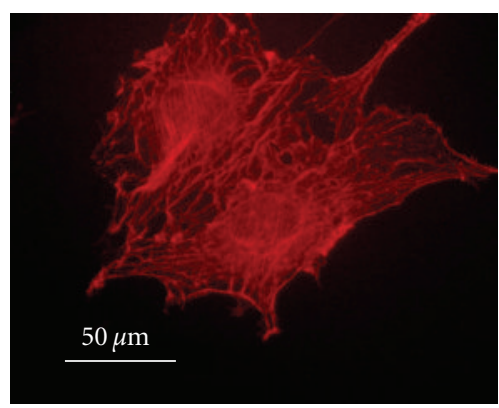

(f)

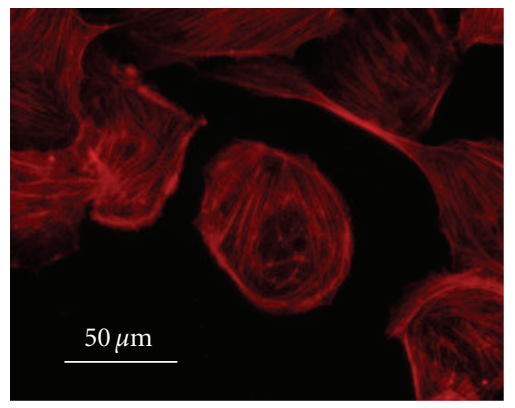

(i)

FIGURE 4: Distribution of actin filaments in cultured melanophores and fibroblasts, revealed by immunoreactivity. Scale bar $=50 \mu \mathrm{m}$. $(\mathrm{a}-\mathrm{c})$ : pigmented melanophores with aggregated pigment. (d-f): depigmented melanophores. (g-i): fibroblasts.

pigment is making cells more sensitive to the cytoskeletal toxicity of HQ.

The effects of $100 \mu \mathrm{M}$ HQ was severe. The cells' ability to attach to the surface was markedly affected, making it impossible to determine any morphological effects on microtubules and actin filaments because of the detachment of the cells both before and during the immunostaining procedure. Adhesion is well known to be actin dependent [16], and its decrease implies an interaction of HQ with actin or actinbinding proteins, which has been shown in other cells as well [1-3]. In cells with preaggregated pigment, addition of $100 \mu \mathrm{M} \mathrm{HQ}$ induced a loosening of the central pigment mass, similar to what can be seen when microtubules are depolymerised $[13,15]$. However, since we were unable to perform immunocytochemistry on cells incubated with $100 \mu \mathrm{M} \mathrm{HQ}$, no clear conclusions can be drawn about the reason for this.
Few studies have addressed the effects of HQ on microtubules, but HQ has been found to be a weak inhibitor of microtubule assembly in vitro [17]. The proportion of cells in $S$ phase is furthermore significantly increased after treatment with moderate doses of HQ, possibly due to effects on the microtubule distribution [18]. Rearrangement of filamentous actin in cells treated with nonlethal doses of HQ has been reported. In retinal epithelium cells nonlethal oxidative injury with HQ induced blebbing and formation of actin aggregates mediated by phosporylation of Hsp27 $[19,20]$. Even if HQ has dramatic effects on microtubule organization and induces a loss of actin filaments in the present study, we cannot completely exclude that HQ exerts a direct effect on the molecular motors responsible for aggregation and dispersion. To our knowledge, functional studies of the effects on HQ on dynein, kinesin, and myosin have not been performed. However, HQ is known to react 
with sulfhydryl-groups $[21,22]$, and the function of the motors is inhibited by sulfhydryl reactive agents [23].

Large amounts of released melanosomes were found in the culture medium of cells incubated in $100 \mu \mathrm{M}$ HQ (data not shown), an effect which could be caused by either a stimulation of the release of melanosomes, or a rupture of the cell membrane increasing melanosome leakage. Previous studies on cultured mouse melanomas and melanophores in goldfish skin using HQ concentrations ranging from 10 to $400 \mu \mathrm{M}$ have shown vacuolisation of the cytoplasm and clumping of granules [24, 25]. Chavin [24] also reported a release of melanin aggregates as a result of cell lysis induced by HQ. In mammalian and amphibian skin, melanosomes are released and taken up by surrounding skin cells to darken the skin [26-31]. One mechanism for bleaching of the skin could be if melanosome transfer to surrounding skin cells is affected by HQ.

HQ has been the standard chemical for treatment of hyperpigmentation for more than 50 years [32]. Subchronic treatment with $\mathrm{HQ}$ for several weeks results in reduction in melanin content and degeneration of melanocytes [33]. In the present study, cells have been incubated with HQ for $24 \mathrm{~h}$, and we have not observed a decrease in melanophore pigmentation.

The oxidation products of $\mathrm{HQ}$ are quinones and reactive oxygen species (ROS), which lead to an oxidative damage of membrane lipids and proteins, including tyrosinase [11]. Glutathione (GSH) is known to quench ROS and protect cells from toxic compounds [34], and when synthesis of GSH is inhibited, the inhibitory effects of HQ on tyrosinase activity, and melanin content are potentiated [35]. It has been previously shown that oxidative stress activates cytotoxic mechanisms that cause cytoskeletal alterations [36], thereby possibly affecting intracellular melanosome transport. Here we have shown that tyrosinase is not the sole cellular target for HQ. However, by comparing the effects of HQ on pigmented and depigmented melanophores and fibroblasts we found that nonpigmented cells are for some reason less sensitive to HQ. In pigmented melanophores, it affects the intracellular organization of actin filaments and microtubules dramatically and thereby affects the cell's ability not only to transport melanosomes but also probably other important cellular cytoskeletal dependent processes. Due to the importance of the cytoskeleton in all cells and across species, our data has to be considered in the discussions about the use of HQ for depigmentation.

\section{Acknowledgments}

The work was financially supported by Stiftelsen Längmanska Kulturfonden, Stiftelsen Lars Hiertas Minne, and Adlerbertska Forskningsstiftelsen.

\section{References}

[1] X. Li, Z. Zhuang, J. Liu, H. Huang, Q. Wei, and X. Yang, "Proteomic analysis to identify the cellular responses induced by hydroquinone in human embryonic lung fibroblasts," Toxicology Mechanisms and Methods, vol. 16, no. 1, pp. 1-6, 2006.
[2] O. Alcazar, A. M. Hawkridge, T. S. Collier et al., "Proteomics characterization of cell membrane blebs in human retinal pigment epithelium cells," Molecular and Cellular Proteomics, vol. 8, no. 10, pp. 2201-2211, 2009.

[3] S. N. Sarma, Y.-J. Kim, and J.-C. Ryu, "Differential gene expression profiles of human leukemia cell lines exposed to benzene and its metabolites," Environmental Toxicology and Pharmacology, vol. 32, no. 2, pp. 285-295, 2011.

[4] B. Kasraee, "Peroxidase-mediated mechanisms are involved in the melanocytotoxic and melanogenesis-inhibiting effects of chemical agents," Dermatology, vol. 205, no. 4, pp. 329-339, 2002.

[5] Y. M. Olumide, A. O. Akinkugbe, D. Altraide et al., "Complications of chronic use of skin lightening cosmetics," International Journal of Dermatology, vol. 47, no. 4, pp. 344-353, 2008.

[6] T.-J. Yoon, T. C. Lei, Y. Yamaguchi, J. Batzer, R. Wolber, and V. J. Hearing, "Reconstituted 3-dimensional human skin of various ethnic origins as an in vitro model for studies of pigmentation," Analytical Biochemistry, vol. 318, no. 2, pp. 260269,2003

[7] C. J. Smith, K. B. O'Hare, and J. C. Allen, "Selective cytotoxicity of hydroquinone for melanocyte-derived cells is mediated by tyrosinase activity but independent of melanin content," Pigment Cell Research, vol. 1, no. 6, pp. 386-389, 1988.

[8] Z. M. Hu, Q. Zhou, T.-C. Lei, S.-F. Ding, and S.-H. Xu, "Effects of hydroquinone and its glucoside derivatives on melanogenesis and antioxidation: biosafety as skin whitening agents," Journal of Dermatological Science, vol. 55, no. 3, pp. 179-184, 2009.

[9] P. G. Engasser and H. I. Maibach, "Cosmetics and dermatology: bleaching creams," Journal of the American Academy of Dermatology, vol. 5, no. 2, pp. 143-147, 1981.

[10] P. R. Hull and P. R. Procter, "The melanocyte: an essential link in hydroquinone-induced ochronosis," Journal of the American Academy of Dermatology, vol. 22, no. 3, pp. 529-531, 1990.

[11] S. Briganti, E. Camera, and M. Picardo, "Chemical and instrumental approaches to treat hyperpigmentation," Pigment Cell Research, vol. 16, no. 2, pp. 101-110, 2003.

[12] S. Aspengren, H. N. Sköld, and M. Wallin, "Different strategies for color change," Cellular and Molecular Life Sciences, vol. 66, no. 2, pp. 187-191, 2009.

[13] S. Aspengren, L. Wielbass, and M. Wallin, "Effects of acrylamide, latrunculin, and nocodazole on intracellular transport and cytoskeletal organization in melanophores," Cell Motility and the Cytoskeleton, vol. 63, no. 7, pp. 423-436, 2006.

[14] D. Hedberg and M. Wallin, "Effects of Roundup and glyphosate formulations on intracellular transport, microtubules and actin filaments in Xenopus laevis melanophores," Toxicology in Vitro, vol. 24, no. 3, pp. 795-802, 2010.

[15] S. L. Rogers and V. I. Gelfand, "Myosin cooperates with microtubule motors during organelle transport in melanophores," Current Biology, vol. 8, no. 3, pp. 161-164, 1998.

[16] S. D. Blystone, "Integrating an integrin; a direct route to actin," Biochimica et Biophysica Acta, vol. 1692, no. 2-3, pp. 47-54, 2004.

[17] M. Wallin and B. Hartley-Asp, "Effects of potential aneuploidy inducing agents on microtubule assembly in vitro," Mutation Research, vol. 287, no. 1, pp. 17-22, 1993.

[18] Y. J. Kim, H. D. Woo, B. M. Kim et al., "Risk assessment of hydroquinone: differential responses of cell growth and lethality correlated to hydroquinone concentration," Journal of Toxicology and Environmental Health: Part A, vol. 72, no. 21-22, pp. 1272-1278, 2009. 
[19] N. Strunnikova, C. Zhang, D. Teichberg et al., "Survival of retinal pigment epithelium after exposure to prolonged oxidative injury: a detailed gene expression and cellular analysis," Investigative Ophthalmology and Visual Science, vol. 45, no. 10, pp. 3767-3777, 2004.

[20] M. Pons, S. W. Cousins, K. G. Csaky, G. Striker, and M. E. Marin-Castaño, "Cigarette smoke-related hydroquinone induces filamentous actin reorganization and heat shock protein 27 phosphorylation through p38 and extracellular signalregulated kinase $1 / 2$ in retinal pigment epithelium: implications for age-related macular degeneration," American Journal of Pathology, vol. 177, no. 3, pp. 1198-1213, 2010.

[21] K. Kageyama, Y. Onoyama, and E. Kano, "Effects of methyl mercuric chloride and sulfhydryl inhibitors on phospholipid synthetic activity of lymphocytes," Journal of Applied Toxicology, vol. 6, no. 1, pp. 49-53, 1986.

[22] D.-X. Shen, X. Shi, J.-L. Fu, Y.-M. Zhang, and Z.-C. Zhou, "The role of thiol reduction in hydroquinone-induced apoptosis in HEK293 cells," Chemico-Biological Interactions, vol. 145, no. 2, pp. 225-233, 2003.

[23] C. H. Martenson, A. Odom, M. P. Sheetz, and D. G. Graham, "The effect of acrylamide and other sulfhydryl alkylators on the ability of dynein and kinesin to translocate microtubules in vitro," Toxicology and Applied Pharmacology, vol. 133, no. 1, pp. 73-81, 1995.

[24] W. Chavin, "Effects of hydroquinone and of the hypophysectomy upon the pigment cells of black goldfish," Journal of Pharmacology and Experimental Therapeutics, vol. 142, pp. 275-290, 1963.

[25] F. Hu, "The influence of certain hormones and chemicals on mammalian pigment cells," Journal of Investigative Dermatology, vol. 46, no. 1, pp. 117-124, 1966.

[26] S. Aspengren, D. Hedberg, and M. Wallin, "Studies of pigment transfer between Xenopus laevis melanophores and fibroblasts in vitro and in vivo," Pigment Cell Research, vol. 19, no. 2, pp. 136-145, 2006.

[27] J. T. Bagnara, "Comparative anatomy and physiology of pigment cells in nonmammalian tissues," in The Pigmentary System, pp. 9-40, Oxford University Press, Oxford, UK, 1998.

[28] R. E. Boissy, "Melanosome transfer to and translocation in the keratinocyte," Experimental Dermatology, vol. 12, no. 2, pp. 512, 2003.

[29] M. E. Hadley and W. C. Quevedo, "The role of epidermal melanocytes in adaptive color changes in amphibians," in Advances in Biology of Skin, pp. 337-358, Pergamon Press, Glasgow, UK, 1967.

[30] K. Jimbow and S. Sugiyama, "Melanosomal translocation and transfer," in The Pigmentary System, pp. 107-114, Oxford University Press, Oxford, UK, 1998.

[31] M. Seiberg, "Keratinocyte-melanocyte interactions during melanosome transfer," Pigment Cell Research, vol. 14, no. 4, pp. 236-242, 2001.

[32] R. M. Halder and G. M. Richards, "Topical agents used in the management of hyperpigmentation," Skin Therapy Letter, vol. 9, no. 6, pp. 1-3, 2004.

[33] A. P. DeCaprio, "The toxicology of hydroquinone-relevance to occupational and environmental exposure," Critical Reviews in Toxicology, vol. 29, no. 3, pp. 283-330, 1999.

[34] D. A. Dickinson, D. R. Moellering, K. E. Iles et al., "Cytoprotection against oxidative stress and the regulation of glutathione synthesis," Biological Chemistry, vol. 384, no. 4, pp. 527-537, 2003.

[35] J. L. Bolognia, S. A. Sodi, M. P. Osber, and J. M. Pawelek, "Enhancement of the depigmenting effect of hydroquinone by cystamine and buthionine sulfoximine," British Journal of Dermatology, vol. 133, no. 3, pp. 349-357, 1995.

[36] G. Bellomo and F. Mirabelli, "Oxidative stress and cytoskeletal alterations," Annals of the New York Academy of Sciences, vol. 663, pp. 97-109, 1992. 

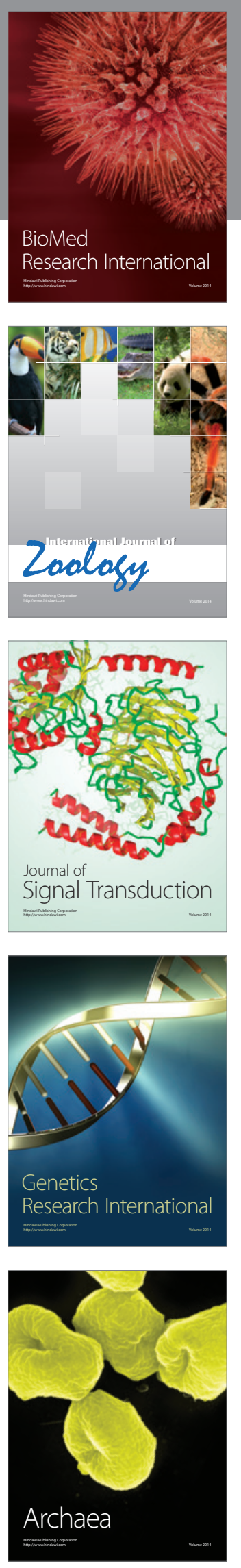
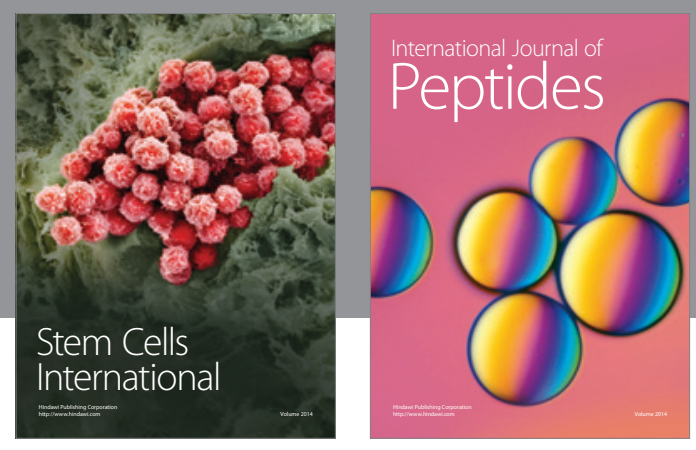

Submit your manuscripts at

http://www.hindawi.com
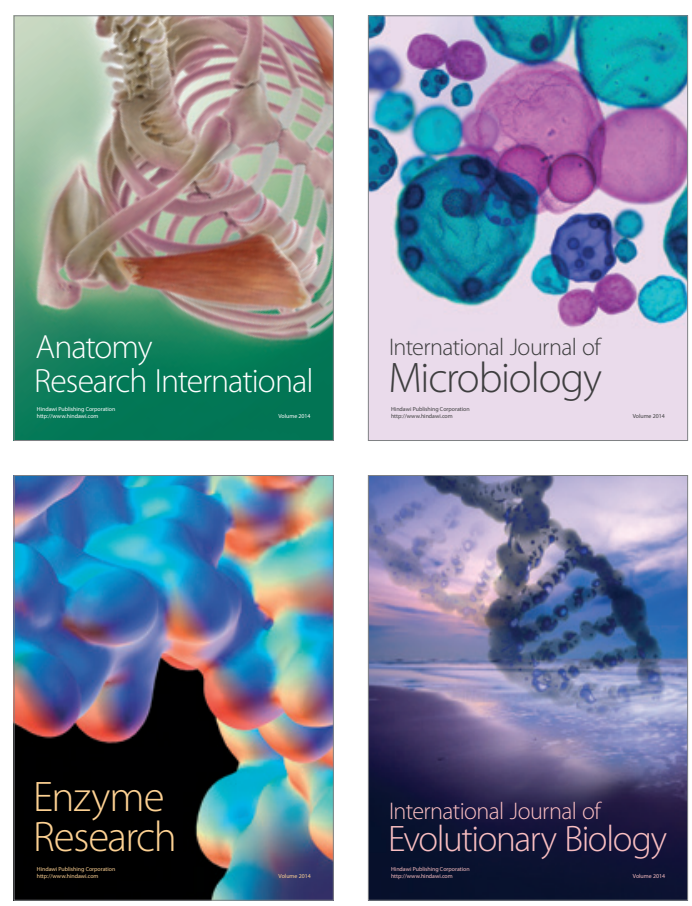
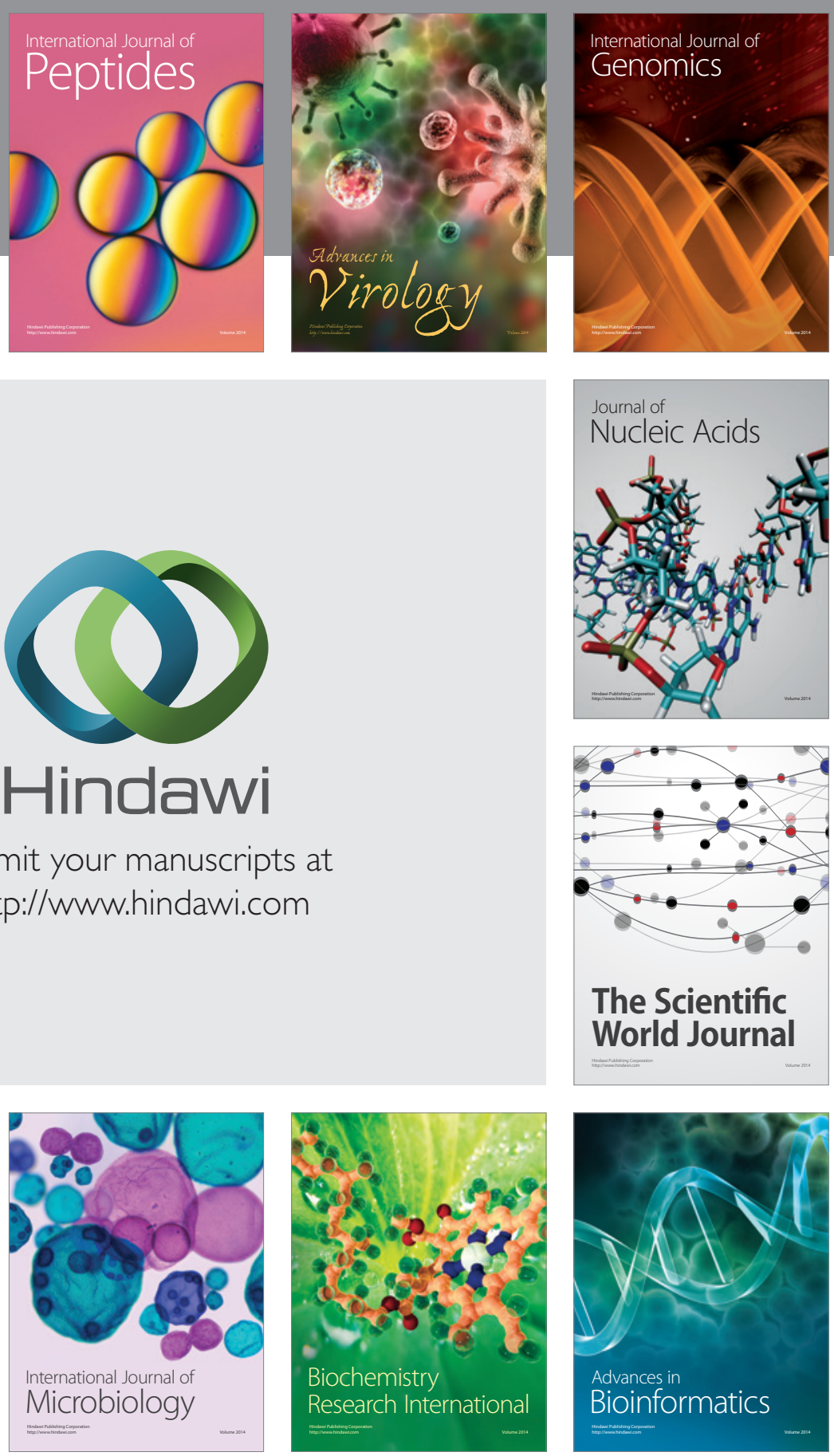

The Scientific World Journal
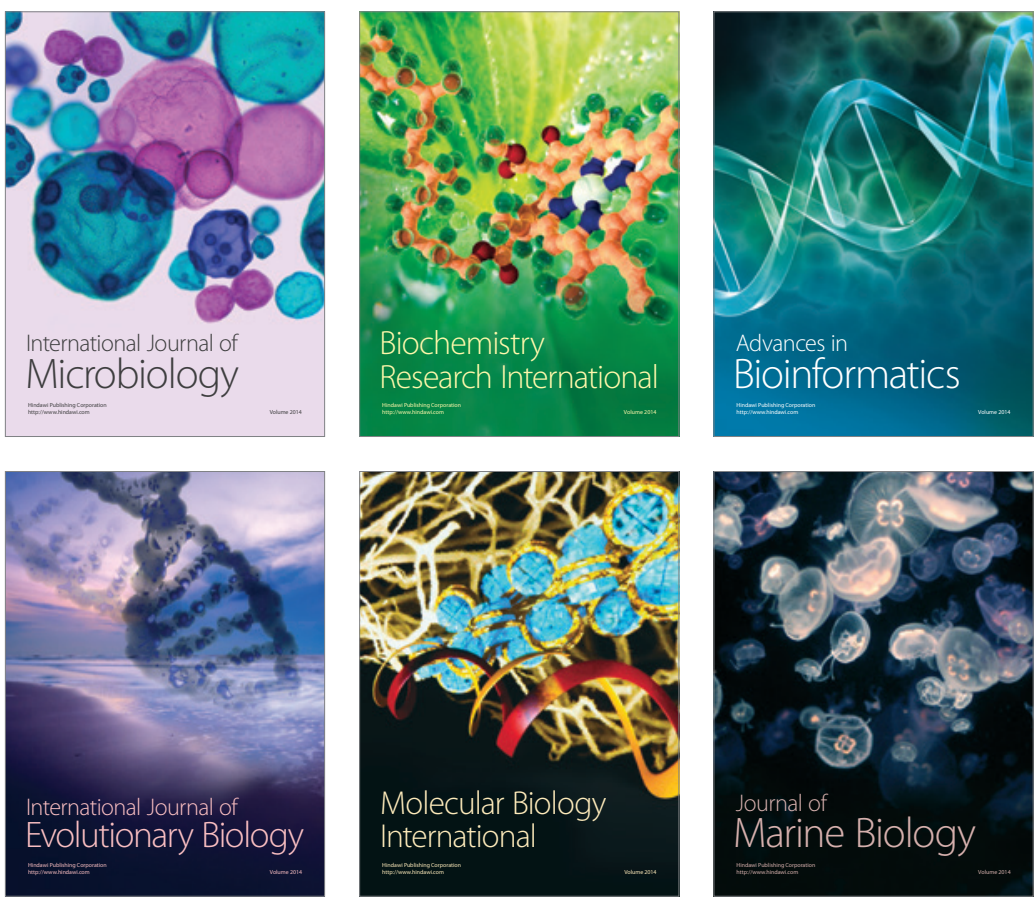